THE INDUSTRIAL INSTITUTE FOR ECONOMIC AND SOCIAL RESEARCH

WORKING PAPER No. 467,1996

HIGH-TECHNOLOGY

SUBSIDIES IN GENERAL EQUILIBRIUM: A SECTORSPECIFIC APPROACH

BY KAROLINA EKHOLM AND JOHAN TORSTENSSON 


\title{
High-Technology Subsidies in General Equilibrium: A Sector-Specific Approach*
}

\author{
Karolina Ekholm \\ The Industrial Institute for Economic and Social Research (IUI) and Lund University \\ Johan Torstensson \\ Lund University
}

September 1996

Correspondence: Karolina Ekholm, IUI, P.O. Box 5501, S-114 85 Stockholm, e-mail: karolinae@iui and Johan Torstensson, Department of Economics, Lund University, P.O. Box 7082, S-220 07 Lund, e-mail: johan.torstensson@nek.lu.se.

\begin{abstract}
We use a specific-factor model to examine the conditions under which policymakers are able to increase aggregate production of high-tech goods by production or R\&D-subsidies in the short and long-run. The difficulties for the policy-makers in designing a subsidy scheme that succeeds in expanding aggregate high-tech production involve taking into account the trade-off between resources used in $R \& D$ and production of high-tech goods, the relative impact of different R\&D activities on productivity, and the ease with which resources may be attracted from the non-high-tech sector of the economy to the various high-tech industries.
\end{abstract}

JEL Classifications: F11, F12

\footnotetext{
* We thank two anonymous referees and participants at seminars in International Economics in Lund, at CREDIT in Nottingham, and at IUI (The Industrial Institute for Economic and Social Research) for valuable comments and suggestions. We have also benefited from discussions with Peter Neary. Financial support from the Nordic Economic Research Council and the Tore Browaldh foundation is gratefully acknowledged.
} 


\section{INTRODUCTION}

Promotion of high-tech industries is currently popular among policy-makers. The intellectual basis for such a policy has been provided by strategic trade policy models. The underlying idea of strategic trade policies is to expand production in certain sectors, such as the high-tech sector, and thereby better exploit positive externalities or to switch profits from foreign to domestic firms. ${ }^{1}$ However, for various reasons it seems difficult to ensure that the implementation of high-tech promotion actually leads to an improvement in welfare. To begin with, the results of strategic trade policy models are known generally not to be robust to changes in the critical assumptions. Furthermore, a perhaps more fundamental problem seems to be that countries that promote their high-tech firms cannot even be sure that this will lead to an increase in high-tech production.

Most strategic trade policy models have been presented in a partial equilibrium framework. ${ }^{2}$ However, although very useful for studying the exact prerequisites for welfare-enhancing trade policies in individual industries, partial equilibrium analysis does not offer any insights into the interaction between the different activities that are necessary for the production of high-tech goods, e.g. research and development (R\&D) and direct production. Nor does it offer insights into the interaction between different high-tech industries or between the high-tech industries and the rest of the economy. But such insights are important if we want to understand why policies undertaken to promote high-tech industries are not always successful even in the sense of expanding high-tech production.

In this paper, we analyse the circumstances in which high-tech subsidies are likely to be successful in expanding high-tech production in a sector-specific general equilibrium framework. If resources cannot easily move from other sectors of the economy, the encouragement of certain high-tech industries, or certain activities within the high-tech industries, may lead mainly to a reallocation of resources within the high-tech sector. Our

\footnotetext{
${ }^{1}$ e.g. Brander \& Spencer (1985), Krugman (1984, 1987), Brander (1995).

${ }^{2}$ Including the original strategic trade policy models presented by Brander \& Spencer (1983), (1985).
} 
study is akin to those by Dixit \& Grossman (1986), Flam \& Helpman (1987), and Markusen (1989), (1990), where industrial policies are examined in general-equilibrium models. However, our study differs from those studies in two respects. First, we explicitly examine not only the trade-off between resources used in different high-tech industries, but also the trade-off between production of high-tech goods and R\&D. Secondly, we allow for inter-industry spillovers of R\&D-activities. ${ }^{3}$ Accordingly, it is not only the industry's own R\&D efforts that affect productivity, but the R\&D efforts of other industries as well. Since we show that high-tech promoting policies do not necessarily increase high-tech production, the general tenor of our results casts further doubts on the benefits of a strategic trade policy.

The rest of the paper is organised as follows: In section II we present the model. Section III analyses the effects of both targeted and uniform subsidies to R\&D and the production of high-tech goods when all resources are immobile between the R\&D sector and the final goods sector. In section IV, we perform the same analysis but allow resources to be mobile between all sectors of the economy. Further, we analyse a special case in section $\mathrm{V}$ and discuss the results and some extensions in section VI. Our conclusions are presented in section VII.

\section{THE MODEL}

Consider a small open economy with three industries that produce final goods. We refer to these industries as the final goods sector. Two of the final goods industries are high-tech industries whose output is denoted $X_{1}$ and $X_{2}$, respectively. The third industry can be thought of as a traditional industry, i.e., an aggregate of the rest of the economy. Output in the traditional industry is denoted $X_{3}$. Free entry and exit prevail in all industries.

${ }^{3}$ Leahy \& Neary (1996) analyse industrial policy in a strategic trade model with inter-industry R\&D spillovers. 
The technology used in the traditional industry is assumed to be given, whereas the technology in the high-tech industries is determined by the amount of R\&D undertaken in the economy. Total $R \& D$ can be divided into $R \& D$ directed towards industry 1 and $R \& D$ directed towards industry 2 . Output of R\&D directed towards industry 1 is denoted $R_{1}$ and output of R\&D directed towards industry 2 is denoted $R_{2}$. We refer to these two activities as the $R \& D$ sector.

Assume that in the short-run, there are two primary factors of production; workers and scientists; both of which are mobile between industries, but not between the two sectors. Workers are required to produce the three finished goods, while scientists are required for R\&D. In the short-run, workers cannot be used in R\&D nor scientists in the final goods sectors. In the long-run, these factors are however completely mobile between all activities and industries. ${ }^{4}$ Moreover, there is industry-specific capital in fixed supplies in all industries in both the short and long-run. However, in an extension of the analysis, we also allow for endogenously determined capital supplies.

The production functions are specified as follows:

$$
\begin{array}{ll}
X_{i}=F^{i}\left(K_{X i}, N_{i}\right) \Pi_{i}\left(R_{1}, R_{2}\right) & \forall i=1,2 \\
X_{3}=F^{3}\left(K_{X 3}, N_{3}\right) & \\
R_{j}=G^{j}\left(K_{R j}, S_{j}\right) & \forall j=1,2
\end{array}
$$

where $N$ and $S$ denote workers and scientists, respectively; $K_{X i} ; i=1,2,3$; are the industry-specific factors in final goods production; $K_{R j} ; j=1,2$; are the industry-specific factors in $\mathrm{R} \& \mathrm{D}$; the functions $\Pi_{i}(\cdot) ; i=1,2$; are increasing in both their arguments and

\footnotetext{
${ }^{4}$ Because we carry out a comparative-static analysis, our model lacks explicit dynamics. Nevertheless, thinking of different comparative-static effects as occurring over time may offer useful insights. According to Neary (1978), the sector-specific model may be appropriate for short-run analysis since capital cannot be costlessly transferred from one sector to another. In the long-run, changes in capital rentals may produce changes in the different sectors' capital stocks.
} 
show the productivity effects of $\mathrm{R} \& \mathrm{D}$; and, finally, the functions $F^{i}(\cdot) ; i=1,2,3$; and $G^{j}(\cdot) ; j=1,2$ are linearly homogenous and have the standard properties of production functions.

We start from an initial equilibrium in which firms are assumed to have optimised their production and their expenditures on $R \& D$ (although we do not explicitly model the process by which firms allocate their private R\&D-expenditures). We simply assume that output in the two R\&D industries is determined by profit-maximising behaviour on the part of the "producers" of R\&D and that the price of a unit of output of R\&D exclusive of any subsidies is constant throughout the analysis. What we study are the effects of marginal government subsidies to R\&D and the production of high-tech goods For simplicity's sake, we assume that lump-sum taxes are available to finance these subsidies. The government offers ad valorem subsidies of $q_{1}$ and $q_{2}$ for R\&D directed towards industry 1 and 2 , respectively, and they offer ad valorem subsidies of $s_{1}$ and $s_{2}$ for actual production of hightechnology products.

Given these assumptions, equilibrium real returns to the mobile factors are equal to their physical marginal product. Hence, the following first-order conditions for profit maximisation apply:

$$
\begin{array}{ll}
\frac{w_{N}}{\Pi_{i}\left(R_{1}, R_{2}\right) P_{i}\left(1+s_{i}\right)}=f_{i}\left(\frac{K_{X i}}{N_{i}}\right) ; & \forall i=1,2 \\
\frac{w_{N}}{P_{3}}=f_{3}\left(\frac{K_{X 3}}{N_{3}}\right) & \\
\frac{w_{S}}{P_{R j}\left(1+q_{j}\right)}=g_{j}\left(\frac{K_{R j}}{S_{j}}\right) ; & \forall j=1,2
\end{array}
$$

where $f_{i}(\cdot)$ and $g_{j}(\cdot)$ are the marginal product functions with the usual properties that $f_{i}^{\prime}<0$ and $g_{j}^{\prime}<0$. It is assumed that $\partial \Pi_{1} / \partial R_{1}>\partial \Pi_{2} / \partial R_{1}$ and $\partial \Pi_{2} / \partial R_{2}>\partial \Pi_{1} / \partial R_{2}$, i.e. that $\mathrm{R} \& \mathrm{D}$ 
has a stronger productivity-raising effect on its own industry than on the other high-tech industry.

Assuming that goods prices are given and that initial industrial subsidies are zero, differentiation of the first-order conditions in (4) - (6) yields:

$$
\begin{array}{ll}
\hat{w}_{N}-\mathrm{d} s_{i}-\hat{\Pi}_{i}=\frac{1}{\rho_{X i}}\left(\hat{K}_{X i}-\hat{N}_{i}\right) ; & \forall i=1,2 \\
\hat{w}_{N}=\frac{1}{\rho_{X 3}}\left(\hat{K}_{X 3}-\hat{N}_{3}\right) & \\
\hat{w}_{S}-\mathrm{d} q_{j}=\frac{1}{\rho_{R j}}\left(\hat{K}_{R j}-\hat{S}_{j}\right) ; & \forall j=1,2
\end{array}
$$

where a ${ }^{\wedge}$ over a variable denotes a relative change in that variable, and the coefficients $\rho_{X i}$ and $\rho_{R j}$ are the elasticities of the demand for workers and scientists, respectively, with respect to changes in their marginal product (or the elasticities of workers' and scientists' marginal product curves; see Jones, 1971). ${ }^{5}$

A change in $\Pi_{i}$ is determined by changes in $R_{I}$ and $R_{2}$ according to:

$$
\hat{\Pi}_{1}=\varepsilon_{1} \hat{R}_{1}+\beta_{2} \varepsilon_{2} \hat{R}_{2} \quad \hat{\Pi}_{2}=\beta_{1} \varepsilon_{1} \hat{R}_{1}+\varepsilon_{2} \hat{R}_{2}
$$

where $\varepsilon_{i}$ is the elasticity of $\Pi_{i}$ with respect to a change in $R_{i}$, and the parameter $\beta_{i}$, which is defined as $\beta_{i} \equiv\left(\partial \Pi_{j} / \partial R_{i}\right) \Pi_{i} /\left(\partial \Pi_{i} / \partial R_{i}\right) \Pi_{j} ; i=1,2 ; j=1,2 ; i \neq j$, shows the fraction of the productivity effect from the industry's own R\&D that affects factor productivity in the other high-tech industry. The term $\varepsilon_{i} \hat{R}_{i}$ in (10) reflects the change in factor input requirements that is caused by a change in the industry's own R\&D. We will refer to this effect as the own effect of R\&D. If we assume that the technology factor is initially identical

${ }^{5}$ These elasticities are defined as $\rho_{X i} \equiv \frac{\mathrm{d}\left(K_{X i} / N_{i}\right) \quad f_{i}}{\mathrm{~d} f_{i}\left(K_{X i} / N_{i}\right)}$ and $\rho_{R j} \equiv \frac{\mathrm{d}\left(K_{R j} / S_{j}\right) g_{j}}{\mathrm{~d} g_{j}\left(K_{R j} / S_{j}\right)}$. 
in the two high-tech industries, $\beta_{i}$ takes a value between zero and one. The term $\beta_{i} \varepsilon_{i} \hat{R}_{i}$ in (10) then reflects the changes in factor input requirements in industry $i$ that is caused by a change in the other high-technology industry's $R \& D$. We will refer to this effect as the spill-over effect of R\&D.

In the short-run, when labour and scientists are immobile between the production and R\&D sector, equations (11) and (12) show the conditions for equilibrium in factor markets:

$$
\begin{aligned}
& N=N_{1}+N_{2}+N_{3} \\
& S=S_{1}+S_{2}
\end{aligned}
$$

If we differentiate (11) - (12) on the assumption of fixed supplies of $N$ and $S$, and then substitute (7) - (9) into the resulting expressions, assuming fixed supplies of the industryspecific factors, we get:

$$
\begin{aligned}
& \lambda_{N 1} \rho_{X 1}\left(\hat{w}_{N}-\mathrm{d} s_{1}-\hat{\Pi}_{1}\right)+\lambda_{N 2} \rho_{X 2}\left(\hat{w}_{N}-\mathrm{d} s_{2}-\hat{\Pi}_{2}\right)+\lambda_{N 3} \rho_{X 3} \hat{w}_{N}=0 \\
& \lambda_{S 1} \rho_{R 1}\left(\hat{w}_{S}-\mathrm{d} q_{1}\right)+\lambda_{S 2} \rho_{R 2}\left(\hat{w}_{S}-\mathrm{d} q_{2}\right)=0
\end{aligned}
$$

where $\lambda_{N i}$ is the fraction of the total supply of labour that is used in the production of good $i$ and $\lambda_{S j}$ the fraction of the total supply of scientists that is used in R\&D in industry $j$.

If we differentiate the production functions in (1) - (3) on the assumption of fixed supplies of industry-specific factors and then substitute (7) - (9) into the resulting expressions we get:

$$
\begin{aligned}
& \hat{X}_{i}=\left(1+\varphi_{X i}\right) \hat{\Pi}_{i}+\varphi_{X i}\left(\mathrm{~d} s_{i}-\hat{w}_{N}\right) \quad \forall i=1,2 \\
& \hat{X}_{3}=-\varphi_{X 3} \hat{w}_{N}
\end{aligned}
$$




$$
\hat{R}_{j}=\varphi_{R j}\left(\mathrm{~d} q_{j}-\hat{w}_{S}\right) \quad \forall j=1,2
$$

where $\varphi_{X i}$, defined as $\varphi_{X i} \equiv \theta_{N i} \rho_{X i} ; i=1,2,3$; is the price elasticity of output in final goods industry $i$, and $\varphi_{R j}$, defined as $\varphi_{R j} \equiv \theta_{S j} \rho_{R j} ; j=1,2$; is the price elasticity of R\&D in industry $j$. The coefficient $\theta_{N i}$ is the distributive share of workers in industry $i$ and $\theta_{S j}$ is the distributive share of scientists in industry $j$.

By substituting (17) into (10), we get:

$$
\hat{\Pi}_{1}=\phi_{1}\left(\mathrm{~d} q_{1}-\hat{w}_{S}\right)+\beta_{2} \phi_{2}\left(\mathrm{~d} q_{2}-\hat{w}_{S}\right) \quad \hat{\Pi}_{2}=\beta_{1} \phi_{1}\left(\mathrm{~d} q_{1}-\hat{w}_{S}\right)+\phi_{2}\left(\mathrm{~d} q_{2}-\hat{w}_{S}\right)
$$

In these expressions, the coefficient $\phi_{i}$ is defined as $\phi_{i} \equiv \varphi_{R i} \varepsilon_{i}$, which is a measure of the own effect of R\&D that results from a change in the producer price of the industry's own $\mathrm{R} \& \mathrm{D}$. Consequently, $\beta_{i} \phi_{i}$ is a measure of the spill-over effects that result from a change in the producer price of the industry's own R\&D.

By substituting (18) into (13), and then solving for the relative change in the wage rate for workers by substituting (14) into the resulting equation, we get:

$$
\begin{aligned}
\hat{w}_{N}=\left[\delta_{N 1}\left(\delta_{S 2} \phi_{1}-\beta_{2} \delta_{S 1} \phi_{2}\right)+\delta_{N 2}\left(\beta_{1} \delta_{S 2} \phi_{1}-\delta_{S 1} \phi_{2}\right)\right] & \left(\mathrm{d} q_{1}-\mathrm{d} q_{2}\right) \\
& +\delta_{N 1} \mathrm{~d} s_{1}+\delta_{N 2} \mathrm{~d} s_{2}
\end{aligned}
$$

where $\delta_{N i}$ and $\delta_{S j} ; i=1,2$; are defined as $\delta_{N i} \equiv \lambda_{N i} \rho_{X i} / \rho_{X}$ and $\delta_{S i} \equiv \lambda_{S i} \rho_{R i} / \rho_{R}$, respectively. The denominator in these coefficients are in turn defined as $\rho_{X} \equiv \lambda_{N 1} \rho_{X 1}+\lambda_{N 2} \rho_{X 2}+\lambda_{N 3} \rho_{X 3}$ and $\rho_{R} \equiv \lambda_{S 1} \rho_{R 1}+\lambda_{S 2} \rho_{R 2}$. They show, respectively, the weighted average of the elasticities of demand for workers and scientists vis-à-vis the changes in their marginal product. The coefficient $\delta_{N i}$ shows the influence of each final goods price on the wage rate of workers $\left(\delta_{N 1}+\delta_{N 2}+\delta_{N 3}=1\right)$ and $\delta_{S j}$ shows the influence of each price of R\&D output on the wage rate of scientists $\left(\delta_{S 1}+\delta_{S 2}=1\right)$.

Analogously, we can write (14), the expression for the equilibrium change in the scientist wage rate as: 


$$
\hat{w}_{S}=\delta_{S 1} \mathrm{~d} q_{1}+\delta_{S 2} \mathrm{~d} q_{2} .
$$

To find the equilibrium changes in output of final goods we first substitute (18) into (15), and then substitute (19) - (20) into the resulting equation and equations (16) - (17).

\section{SHORT-RUN ANALYSIS}

The short-run effects of increased R\&D and production subsidies on factor prices and output are summarised in Table 1.

\section{TABLE 1}

The effect of high-tech promoting subsidies in the short-run

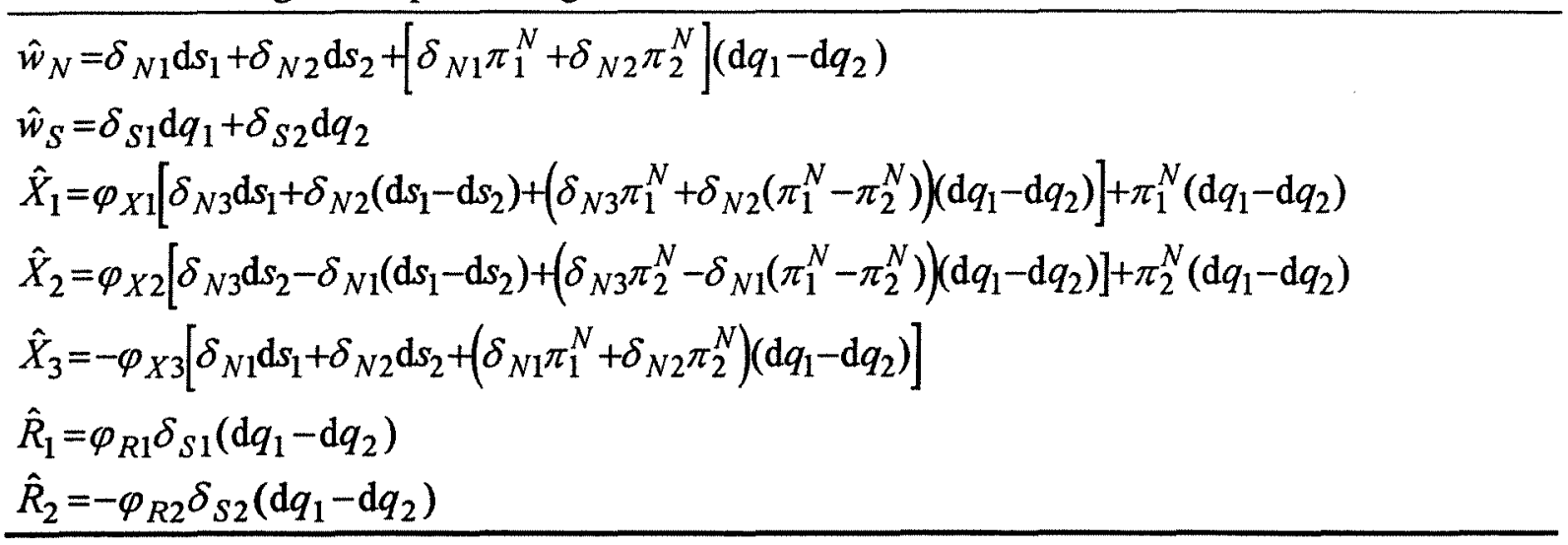

From Table 1 it is evident that the coefficients $\pi_{1}^{N}$ and $\pi_{2}^{N}$ are of crucial importance in relation to the effect of R\&D subsidies. These coefficients are defined as $\pi_{1}^{N} \equiv \delta_{S 2} \phi_{1}-\delta_{S 1} \beta_{2} \phi_{2}$ and $\pi_{2}^{N} \equiv \delta_{S 2} \beta_{1} \phi_{1}-\delta_{S 1} \phi_{2}$, and they show the net effect on labour productivity in industry 1 and 2 , respectively, from changes in $R_{1}$ and $R_{2}$ following an increase in the price ratio between $R \& D$ in industry 1 and industry 2 . To remove the effect of differences of scale on the relative changes of $R_{1}$ and $R_{2}$, let us assume that, initially, the value of output from the two R\&D activities is equal. The signs of $\pi_{1}^{N}$ and $\pi_{2}^{N}$ will then 
depend only on the relative strength of the own and spillover effects of R\&D. ${ }^{6}$ We know from the assumptions made about the strength of spillovers that the inequality $\pi_{1}^{N}>\pi_{2}^{N}$ holds. However, depending on the relative strength of the own and spillover effects of $\mathrm{R} \& \mathrm{D}, \pi_{1}^{N}$ and $\pi_{2}^{N}$ may have opposite signs or they may both be positive or negative. If the output from the R\&D activity whose relative price increases $\left(R_{l}\right)$ is associated with weak own and spillover effects relative to the other R\&D activity, $\pi_{1}^{N}$ and $\pi_{2}^{N}$ are both likely to be negative. Similarly, if $R_{I}$ is associated with relatively strong own and spillover effects, they are both likely to be positive.

\section{Uniform R\&D-subsidies}

As seen in Table 1, a uniform increase in $R \& D$ funding will have no effect on any of the output variables, because in the short-run, there are no resources outside $R \& D$ that can be used for production of $\mathrm{R} \& \mathrm{D}$. If $\mathrm{d} q_{1}=\mathrm{d} q_{2}>0$, the only effect in the R\&D sector will be an increase in the wage rate of scientists. ${ }^{7}$

\section{Uniform Production Subsidies}

According to Table 1, a uniform production subsidy (i.e. $\mathrm{d} s_{1}=\mathrm{d} s_{2}$ ) will lead to an expansion of aggregate high-tech production, provided there is some degree of substitutability of resources between the traditional industry and the high-tech industries. A uniform production subsidy is thus, in the short-run, a more certain way of expanding aggregate high-tech production than a uniform $R \& D$ subsidy. How large the effect on output of high-tech goods is, depends on the size of the terms $\varphi_{X 1} \delta_{N 3}$ and $\varphi_{X 2} \delta_{N 3}$, i.e. it depends on the elasticity of factor substitution in the final goods industries and on how important workers are as an input in these industries. ${ }^{8}$

\footnotetext{
${ }^{6}$ The assumption $P_{R 1} R_{1}=P_{R 2} R_{2}$ implies the equality $\varphi_{R 1} \delta_{S 2}=\varphi_{R 2} \delta_{S 1}$. Using this in the definitions of $\pi_{1}^{N}$ and $\pi_{2}^{N}$ we find that $\operatorname{sign}\left(\pi_{1}^{N}\right)=\operatorname{sign}\left(\varepsilon_{1}-\beta_{2} \varepsilon_{2}\right)$ and $\operatorname{sign}\left(\pi_{2}^{N}\right)=\operatorname{sign}\left(\beta_{1} \varepsilon_{1}-\varepsilon_{2}\right)$.

${ }^{7}$ This corresponds to the case with "pure inflation" in Jones (1971), i.e. an equiproportionate rise in the prices of goods changes factor prices by the same proportionate amount.

${ }^{8}$ From the definitions of the coefficients $\varphi_{X i}$ and $\delta_{N i}$ it follows that their size depends on the size of the elasticities of the demand for workers, on the one hand, and on the industry's worker intensity, on the other.
} 


\section{Targeted $R \& D$-subsidies}

In the case of targeted $R \& D$ subsidies, resources within the $R \& D$ sector will be reallocated so that the targeted $R \& D$ increases and the non-targeted $R \& D$ decreases. To find an expression for the effect on aggregate high-tech production we shall, throughout the analysis, assume that initial prices of high-tech goods are equal to one and that output is the same. ${ }^{9}$ The effect of a targeted R\&D subsidy to industry 1 is then shown by the following expression:

$$
\hat{X}_{1}+\hat{X}_{2}=\left[\pi_{1}^{N}+\pi_{2}^{N}+\delta_{N 3}\left(\varphi_{X 1} \pi_{1}^{N}+\varphi_{X 2} \pi_{2}^{N}\right)\right] \mathrm{d} q_{1}
$$

We can see that there are three effects that determine the total effect on output of high-tech goods. In both industries there are direct productivity effects which in turn lead to changes in output from given inputs. There is also a reallocation effect from workers moving into or out of the traditional industry when productivity changes in high-tech production.

The tendencies of each of these three effects depend on the signs of $\pi_{1}^{N}$ and $\pi_{2}^{N}$. If $R \& D$ in the targeted industry has sufficiently stronger own and spillover effects than $R \& D$ in the other industry for $\pi_{1}^{N}$ and $\pi_{2}^{N}$ to both be positive, (21) will be positive and a targeted R\&D subsidy will be successful in expanding high-tech production. From the last terms in (21), we see that this expansion will be larger, the more easily the high-tech industries can attract workers from the traditional industry. If instead the subsidised industry has relatively weak own and spillover effects so that $\pi_{1}^{N}$ and $\pi_{2}^{N}$ are both negative, the high-tech sector will contract. This contraction will be greater the more easily workers can move between the high-tech sector and the traditional industry. If the strength of own and spillover effects

The elasticity of the demand for workers is positively related to the elasticity of factor substitution (see e.g. Jones 1971).

${ }^{9}$ The assumption that the output initially is of equal value in the two high-tech industries implies that $\varphi_{X 1} \delta_{N 2}=\varphi_{X 2} \delta_{N 1}$. 
are quite similar in the two high-tech industries, $\pi_{1}^{N}$ will be positive and $\pi_{2}^{N}$ negative. The effect on aggregate high-tech production is then less clear-cut. In addition to the magnitude of $\pi_{1}^{N}$ and $\pi_{2}^{N}$, the effect will also depend on how easily the targeted industry can attract workers from the traditional industry and how easily the non-targeted industry can release workers to that industry. Thus, unless we have quite detailed knowledge, in particular about the relative strength of own and spillover effects of $R \& D$, targeted $R \& D$ subsidies may cause a reduction of high-tech output.

\section{Targeted Production Subsidies}

Now, assume instead that industry 1 gets a production subsidy equal to $\mathrm{d} s_{l}$. From Table 1 , we find that $\hat{X}_{1}=\varphi_{X 1}\left(1-\delta_{N 1}\right) \mathrm{d} s_{1}$ and $\hat{X}_{2}=-\varphi_{X 2} \delta_{N 1} \mathrm{~d} s_{1}$. Taken together, this means that $\hat{X}_{1}+\hat{X}_{2}=\varphi_{X 1} \delta_{N 3} \mathrm{~d} s_{1} .{ }^{10}$ Thus, provided that there is some degree of substitutability of resources between the targeted industry and the industry producing traditional goods, aggregate high-tech production will expand. In this case, a scheme of production subsidies that is especially successful in expanding aggregate high-tech production should involve targeting the high-tech industry that can most easily attract workers from the traditional industry.

\section{LONG-RUN ANALYSIS}

In the long-run, we assume that the proportion of the overall labour force that becomes workers and scientists, respectively, responds perfectly to changes in their relative returns. This corresponds to a situation where a given overall supply of labour is mobile between all five different activities in the economy. Factor markets are then in equilibrium when the value of marginal products of labour is equalised across all activities.

\footnotetext{
${ }^{10}$ The effect on aggregate high-tech production is derived by using the equality in the previous footnote and the definition of the $\delta$ 's.
} 
If we denote the wage rate that is now the return to both scientists and workers by $w_{L}$, equilibrium in the factor markets is achieved when the following condition holds:

$$
\begin{array}{r}
\delta_{X 1}\left(\hat{w}_{L}-\mathrm{d} s_{1}-\hat{\Pi}_{1}\right)+\delta_{X 2}\left(\hat{w}_{L}-\mathrm{d} s_{2}-\hat{\Pi}_{2}\right)+\delta_{X 3} \hat{w}+\delta_{R 1}\left(\hat{w}_{L}-\mathrm{d} q_{1}\right) \\
+\delta_{R 2}\left(\hat{w}_{L}-\mathrm{d} q_{2}\right)=0
\end{array}
$$

The coefficients $\delta_{X i}$ and $\delta_{R j}$ in (17) are defined as $\delta_{X i} \equiv \lambda_{X i} \rho_{X i} / \rho$ and $\delta_{R j} \equiv \lambda_{R j} \rho_{R j} / \rho$, respectively, where $\lambda_{X i}$ and $\lambda_{R j}$ are the proportions of the total supply of labour that is used in final production in industry $i$ and in R\&D in industry $j$, respectively, $\rho_{X i}$ and $\rho_{R j}$ are as before the elasticities of demand for the intersectorally mobile factor with respect to changes in its marginal product in final production and R\&D, respectively, and, finally, $\rho$ is the weighted average of these elasticities, i.e., $\rho \equiv \sum_{i=1}^{3} \lambda_{X i} \rho_{X i}+\sum_{j=1}^{2} \lambda_{R j} \rho_{R j}$.

The effects of R\&D subsidies and production subsidies on outputs and the returns to the mobile factors are summarised in Table 2.

\section{TABLE 2}

The effect of high-tech promoting subsidies in the long-run

$$
\begin{aligned}
\hat{w}_{L}= & \frac{1}{\Delta}\left[\delta_{X 1} \mathrm{~d} s_{1}+\delta_{X 2} \mathrm{~d} s_{2}+\left(\delta_{R 1}+\delta_{H 1} \phi_{1}\right) \mathrm{d} q_{1}+\left(\delta_{R 2}+\delta_{H 2} \phi_{2}\right) \mathrm{d} q_{2}\right] \\
\hat{X}_{1}= & \frac{1}{\Delta}\left[\left(\varphi_{X 1}\left(1-\delta_{X 1}\right)+\varphi_{X 1} \delta_{X 2} \pi_{2}^{T}-\delta_{X 1} \pi_{1}^{T}\right) \mathrm{d} s_{1}-\left(\left(1+\varphi_{X 1}\right) \pi_{1}^{T}+\varphi_{X 1}\right) \delta_{X 2} \mathrm{~d} s_{2}+\left\{\phi _ { 1 } \left(\delta_{X}+\varphi_{X 1} \delta_{X 3}\right.\right.\right. \\
& \left.\left.+\left(1-\beta_{1}\right) \varphi_{X 1} \delta_{X 2}\right)-\varphi_{X 1} \delta_{R 1}\right\} \mathrm{d} q_{1}+\left\{\phi_{2}\left(\beta_{2}\left(\delta_{X}+\varphi_{X 1} \delta_{X 3}\right)-\left(1-\beta_{2}\right) \varphi_{X 1} \delta_{X 2}\right)-\varphi_{X 1} \delta_{R 2}\right\} \mathrm{d} q_{2} \\
& \left.+\left(1+\varphi_{X 1}\right)\left(\pi_{1}^{N}+\phi_{1} \delta_{X 2} \phi_{2}\left(1-\beta_{1} \beta_{2}\right)\right)\left(\mathrm{d} q_{1}-\mathrm{d} q_{2}\right)\right] \\
\hat{X}_{2}= & \frac{1}{\Delta}\left[\left(\varphi_{X 2}\left(1-\delta_{X 2}\right)+\varphi_{X 2} \delta_{X 1} \pi_{1}^{T}-\delta_{X 2} \pi_{2}^{T}\right) \mathrm{d} s_{2}-\left(\left(1+\varphi_{X 2}\right) \pi_{2}^{T}+\varphi_{X 2}\right) \delta_{X 1} \mathrm{~d} s_{1}+\left\{\phi _ { 1 } \left(\beta_{1}\left(\delta_{X}+\varphi_{X 2} \delta_{X 3}\right)\right.\right.\right. \\
& \left.\left.-\left(1-\beta_{1}\right) \varphi_{X 2} \delta_{X 1}\right)-\varphi_{X 2} \delta_{R 1}\right\} \mathrm{d} q_{1}+\left\{\phi_{2}\left(\delta_{X}+\varphi_{X 2} \delta_{X 3}+\left(1-\beta_{2}\right) \varphi_{X 2} \delta_{X 1}\right)-\varphi_{X 2} \delta_{R 2}\right\} \mathrm{d} q_{2} \\
& \left.+\left(1+\varphi_{X 2}\right)\left(\pi_{2}^{N}-\phi_{2} \delta_{X 1} \phi_{1}\left(1-\beta_{1} \beta_{2}\right)\right)\left(\mathrm{d} q_{1}-\mathrm{d} q_{2}\right)\right] \\
\hat{X}_{3}= & \frac{\varphi_{X 3}}{\Delta}\left[\delta_{X 1} \mathrm{~d} s_{1}+\delta_{X 2} \mathrm{~d} s_{2}+\left(\delta_{R 1}+\delta_{H 1} \phi_{1}\right) \mathrm{d} q_{1}+\left(\delta_{R 2}+\delta_{H 2} \phi_{2}\right) \mathrm{d} q_{2}\right] \\
\hat{R}_{1}= & -\frac{\varphi_{R 1}}{\Delta}\left[\delta_{X 1} \mathrm{~d} s_{1}+\delta_{X 2} \mathrm{~d} s_{2}-\delta_{X} \mathrm{~d} q_{1}-\left(\delta_{R 2}+\delta_{H 2} \phi_{2}\right)\left(\mathrm{d} q_{1}-\mathrm{d} q_{2}\right)\right] \\
\hat{R}_{2}= & -\frac{\varphi_{R 2}}{\Delta}\left[\delta_{X 1} \mathrm{~d} s_{1}+\delta_{X 2} \mathrm{~d} s_{2}-\delta_{X} \mathrm{~d} q_{2}+\left(\delta_{R 1}+\delta_{H 1} \phi_{1}\right)\left(\mathrm{d} q_{1}-\mathrm{d} q_{2}\right)\right]
\end{aligned}
$$


The coefficient $\delta_{X}$ is defined as $\delta_{X} \equiv \sum_{i=1}^{3} \delta_{X i}$ and it shows how much a uniform increase in the prices of final goods influences the wage rate of labour. The coefficients $\delta_{H 1} \equiv \delta_{X 1}+\beta_{1} \delta_{X 2}$ and $\delta_{H 2} \equiv \beta_{2} \delta_{X 1}+\delta_{X 2}$ show how strongly R\&D directed to industry 1 and 2 , respectively, affects $w_{L}$ through changes in labour's marginal product; while the coefficients $\pi_{1}^{T} \equiv \phi_{1}+\beta_{2} \phi_{2}$ and $\pi_{2}^{T} \equiv \beta_{1} \phi_{1}+\phi_{2}$ show the total effect on labour's marginal product in final production in industry 1 and 2 , respectively, from a marginal increase in both $R_{1}$ and $R_{2}$. The determinant, $\Delta=1+\delta_{H_{1}} \phi_{1}+\delta_{H_{2}} \phi_{2}$, is positive.

\section{Uniform $R \& D$ Subsidies}

We use $\mathrm{d} q$ to denote the uniform R\&D subsidy. The effect on aggregate output of hightechnology goods can be found from expression (23):

$$
\hat{X}_{1}+\hat{X}_{2}=\frac{1}{\Delta}\left[\delta_{X}\left(\pi_{1}^{T}+\pi_{2}^{T}\right)+\delta_{X 3}\left(\varphi_{X 1} \pi_{1}^{T}+\varphi_{X 2} \pi_{2}^{T}\right)-\left(\varphi_{X 1}+\varphi_{X 2}\right) \delta_{R}\right] \mathrm{d} q
$$

where $\delta_{R} \equiv \delta_{R 1}+\delta_{R 2}$ (and shows how much a uniform increase in the return to $\mathrm{R} \& \mathrm{D}$ influences the wage rate of labour). In this expression, the coefficients $\pi_{1}^{T}$ and $\pi_{2}^{T}$ are of crucial importance. They show the total productivity increase brought about by an expansion of $R \& D$ in both high-tech industries. With uniform $R \& D$ subsidies, labour will move to the R\&D sector and technology will improve in both high-tech industries. The first two terms in expression (23) show the direct productivity effect of this increase in R\&D, and the following two terms show the positive indirect effect of the reallocation of labour from the traditional industry following the productivity increase in high-tech production. However, there is also a negative effect from the reallocation of labour from the final production of high-tech goods to R\&D. This effect is shown by the last two terms in (23).

In the long-run, therefore, as opposed to the short-run, a uniform increase in R\&D subsidies may lead to an expansion of aggregate high-tech production. However, this assumes that the expansionary effects of the improvement of technology brought about by 
the increase in $R \& D$ more than outweigh the contractive effects of any reallocation of resources between the production and $\mathrm{R} \& \mathrm{D}$ sector.

\section{Uniform Production Subsidies}

In the long-run case, uniform production subsidies are less certain to be successful in expanding aggregate high-tech production because labour can be drawn from the R\&D sector which will in turn have a negative effect on productivity.

The effect on aggregate output of a uniform production subsidy is shown by expression (24):

$$
\hat{X}_{1}+\hat{X}_{2}=\frac{1}{\Delta}\left[\left(\varphi_{X 1}+\varphi_{X 2}\right)\left(\delta_{R}+\delta_{X 3}\right)-\left(\delta_{X 1}+\delta_{X 2}\right)\left(\pi_{1}^{T}+\pi_{2}^{T}\right)\right] \mathrm{d} s
$$

where $\mathrm{d} s$ is the uniform production subsidy. There are two counteracting effects, as shown by expression (24), and, consequently, the effect of production subsidies is generally ambiguous. The positive terms in (24) show the effect of a reallocation of labour to the subsidised industries from the rest of the economy. The negative terms show the effect on factor productivity of the induced fall in $R_{1}$ and $R_{2}$. Self-evidently, the negative effect of this fall will be larger, the more easily labour is drawn from the $R \& D$ sector to the hightech production and the more productivity in the high-tech industries is affected by changes in $\mathrm{R} \& \mathrm{D}$ (i.e. the higher is $\left[\left(\delta_{X 1}+\delta_{X 2}\right)\left(\pi_{1}^{T}+\pi_{2}^{T}\right)\right]$ ).

\section{Targeted R\&D Subsidies}

Consider now the case of an R\&D subsidy directed towards industry 1 , i.e., $\mathrm{d} q_{1}>0$ and $\mathrm{d} q_{2}=0$. Labour will now be drawn away from the $R \& D$ activity that is not targeted and the direction of the effect on aggregate high-tech production depends in a more complex way on the interaction between industries than in the case of uniform R\&D subsidies. It now becomes important to target the R\&D-activity that has large own and spillover effects and that can also relatively easily draw labour away from the traditional industry. 
The effect on aggregate high-tech production is shown by expression (25):

$$
\begin{aligned}
\hat{X}_{1}+\hat{X}_{2}= & \frac{1}{\Delta}\left[\pi_{1}^{N *}+\pi_{2}^{N *}+\left(\delta_{R 2}+\delta_{X 3}\right)\left(\varphi_{X 1}+\beta_{1} \varphi_{X 2}\right) \phi_{1}\right. \\
& \left.-\delta_{R 1}\left(\left(\varphi_{X 1}+\varphi_{X 2}\right)+\phi_{2}\left(\beta_{2} \varphi_{X 1}+\varphi_{X 2}\right)\right)+\phi_{1} \phi_{2}\left(1-\beta_{1} \beta_{2}\right)\left(\delta_{X 2}-\delta_{X 1}\right)\right] \mathrm{d} q_{1}
\end{aligned}
$$

where $\pi_{1}^{N^{*}} \equiv\left(1-\delta_{R 1}\right) \phi_{1}-\delta_{R 1} \beta_{2} \phi_{2}$ and $\pi_{2}^{N^{*}} \equiv\left(1-\delta_{R 1}\right) \beta_{1} \phi_{1}-\delta_{R 1} \phi_{2}$ show the net effect on productivity in industry 1 and 2 , respectively, from the changes in $R_{1}$ and $R_{2}$ following a relative increase of the price of R\&D in industry 1 . These terms (the first two terms in (25)) thus show the direct net effects on productivity from the changes in $R_{1}$ and $R_{2}$. The likelihood that these net effects are both positive is now greater compared to the short-run case, since the targeted $R \& D$ activity can now expand by drawing resources from all other sectors in the economy, and not only from the non-targeted $R \& D$ activity.

The remaining terms in (25) show indirect reallocation and productivity effects. There is a positive employment effect stemming from the tendency for increased labour productivity as targeted $R \& D$ increases. Resources are attracted to high-tech production from the traditional industry and the non-targeted $R \& D$ activity, as shown by the terms that are multiplied by $\left(\delta_{R 2}+\delta_{X 3}\right)$. However, there are also counteracting effects. Labour is drawn from high-tech production into the subsidised $R \& D$ activity, as shown by the first two negative terms. Furthermore, labour is drawn from the non-targeted R\&D activity. This will have a negative effect on productivity which offsets the positive effect from the expansion of targeted $R \& D$ (this effect is shown by the following two negative terms in (25)).

The last terms in (25) show the indirect effect of the change in labour productivity in high-tech production on the scope for expansion of the targeted $R \& D$ activity. Depending on which of the two high-tech industries is the most labour intensive, this will either extend or limit the scope of an expansion of the targeted R\&D activity, thereby determining the total productivity-improving effect stemming from the increase in $R_{l}$. The changes in $R_{l}$ and $R_{2}$ will certainly lead to an improvement of industry 1 's labour productivity relative to industry 2's, irrespective of whether overall labour productivity improves or not. 
Consequently, if industry 2 (industry 1 ) is the most labour-intensive high-tech industry (i.e. if $\left.\delta_{X 2}>(<) \delta_{X 1}\right)$, the relative worsening (improvement) of productivity in industry 2 (industry 1) will have a relatively large curbing (magnifying) effect on the wage rate, increasing (decreasing) the scope for expanding $R_{I} \cdot{ }^{11}$

Just as in the short-run case, there would seem to be a considerable need for detailed information about the structure of the economy in order to ensure there would be positive effects on aggregate high-tech production. Although the problem of having to substitute one R\&D activity for another is now of lesser importance, in this case, resources may be drawn away from high-tech production into the targeted R\&D-activity. To add some insights into how the outcome is affected by the strength of the effect on productivity from $R \& D$, on the one hand, and the factor intensities and substition elasticities in high-tech production, on the other, we shall in a subsequent section analyse a special case where we disregard any spillover effects and assume that productivity effects from $R \& D$ are similar in the two hightech industries.

\section{Targeted Production Subsidies}

Finally, consider a targeted production subsidy to industry 1 , i.e. $\mathrm{d} s_{1}>0$ and $\mathrm{d} s_{2}=0$. The effect on aggregate high-tech production is shown by expression (26):

$$
\hat{X}_{1}+\hat{X}_{2}=\frac{1}{\Delta}\left[\varphi_{X 1}\left(\delta_{R}+\delta_{X 3}\right)-\delta_{X 1}\left(\pi_{1}^{T}+\pi_{2}^{T}\right)\right] \mathrm{d} s_{1},
$$

The first terms in (26) show the effect of a reallocation of resources from the R\&D sector and the traditional industry to the targeted industry. This reallocation points to an increase in production of high-tech goods. The following terms show the negative effect of a loss of factor productivity when the R\&D sector contracts. Output in the targeted industry may or may not increase, depending on which of these effects is the strongest: the positive 
reallocation effect or the negative productivity effect. Output in the non-targeted high-tech industry is, however, certain to fall, because both the reallocation effect and the productivity effect work towards reducing output. The greater the ease with which labour can move between the targeted industry and the traditional industry, the more final production can expand without reducing R\&D and thereby factor productivity.

\section{A SPECIAL CASE}

The analysis shows that the strength of own and spillover effects from $R \& D$ and the relative ease with which resources can move between sectors are the important factors determining the outcome of different policies. To generate more easily interpreted results, especially in the case of targeted $R \& D$ subsidies, we shall in this section focus on a special case. Let us now disregard spillover effects by setting $\beta_{1}=\beta_{2}=0$, thus focusing on the case where the productivity improvements from $R \& D$ in one high-tech industry are proprietary and have no effect on productivity in the other high-tech industry. ${ }^{12}$ Furthermore, let us assume that the own effects of R\&D are equal in the two industries by setting $\varepsilon_{1}=\varepsilon_{2}=\varepsilon$. Thus, the two high-tech industries can only differ in their factor intensities and elasticities of factor substitution. As before, to remove any effects that occur simply because of scale differences between industries, we assume that, initially, the value of output of both $R \& D$ and final goods are equal in the two high-tech industries (that is, with all prices initially set to one, we assume that $X_{1}=X_{2}$ and $R_{1}=R_{2}$ ). In the long-run case we also add the assumption that the value of the output of R\&D equals the value of the output of final goods (i.e. $X_{I}=X_{2}$ $\left.=R_{1}=R_{2}\right){ }^{13}$

\footnotetext{
12 For instance, R\&D in a high-tech industry such as the aircraft industry may have no effect on productivity in an industry such as pharmaceuticals.

${ }^{13}$ This assumption implies not only the equalities $\varphi_{X i} \delta_{X 2}=\varphi_{X 2} \delta_{X 1}$ and $\varphi_{R i} \delta_{R 2}=\varphi_{R 2} \delta_{R 1}$, but also the equality $\varphi_{X i} \delta_{R j}=\varphi_{R j} \delta_{X i}$.
} 
In the short-run analysis we were able to derive unambiguous results in all cases but the one with targeted R\&D-subsidies. The following expression corresponds to (21) in the previous analysis:

$$
\hat{X}_{1}+\hat{X}_{2}=\delta_{N 3} \delta_{S 2} \varphi_{R 1} \varepsilon\left(\varphi_{X 1}-\varphi_{X 2}\right) \mathrm{d} q_{1}
$$

Expression (27) shows that to expand high-tech production in this special case, the targeted industry should be the one with the higher supply elasticity, i.e. the higher workerintensity and elasticity of substitution. When the productivity improvement in the targeted industry is exactly counteracted by the productivity deterioration in the other high-tech industry, the effect on aggregate high-tech production will only depend on whether the targeted industry can more easily draw workers from the traditional industry than the traditional industry can from the non-targeted high-tech industry.

In the long-run, the effect of production and R\&D subsidies will depend crucially on the size of the productivity effects of $R \& D$. If the elasticity $\varepsilon$, which shows the effect of changes in R\&D on productivity in high-tech production, is greater than one, uniform R\&D subsidies will be more successful in expanding aggregate high-tech production than uniform or targeted production subsidies. The negative effect of resources being drawn out of hightech production into $R \& D$ will in this case be more than compensated for by the resulting increase in factor productivity as R\&D expands. If $\varepsilon$ is lower than one, production subsidies are to be preferred because the positive effect on output from the reallocation of resources from $R \& D$ to high-tech production outweighs the negative effect from the worsening of productivity as the $\mathrm{R} \& \mathrm{D}$ sector contracts. ${ }^{14}$

With a targeted R\&D subsidy, the elasticity $\varepsilon$ interacts with factor-intensities and substitution elasticities in determining the outcome. The following expression, which

\footnotetext{
14 The conditions that $\varepsilon \geq 1$ in the case of a uniform $R \& D$ subsidy and $\varepsilon \leq 1$ in the case of a uniform and targeted production subsidy are sufficient, but not necessary, for a non-negative effect on aggregate high-tech production.
} 
corresponds to (25) in the previous analysis, shows the effect on aggregate high-tech production:

$$
\hat{X}_{1}+\hat{X}_{2}=\frac{\varphi_{R 1}}{\Delta}\left[\delta_{X 3}\left(1+\varphi_{X 1}\right) \varepsilon+\left(\delta_{X 1}+\delta_{X 2}+\left(\varphi_{X 2}-\varphi_{X 1}\right) \delta_{R 2} \varepsilon\right)(\varepsilon-1)\right] \mathrm{d} q_{1}
$$

Expression (28) shows that to expand high-tech production, the industry with the lower (higher) elasticity of supply should be subsidised if $\varepsilon$ is greater (less) than one. If changes in $R \& D$ bring about relatively strong effects on productivity (i.e. if $\varepsilon>1$ ), a reallocation of labour from high-tech production to $R \& D$ will result in increased output of high-tech goods. With a targeted R\&D subsidy such a reallocation is facilitated when the industry with the relatively lower elasticity of supply is targeted. The non-targeted industry, whose productivity worsens, will release a relatively large amount of labour to the R\&D sector at the same time as the expansion of $R \& D$ will not be curbed by large increases in the targeted industry's demand for labour as its productivity improves. On the other hand, if changes in $R \& D$ bring about relatively weak effects on productivity (i.e. if $\varepsilon<1$ ), the output of high-tech goods will fall as we reallocate resources from high-tech production to R\&D. Just as in the short-run case, it would then be better to target the industry that can relatively easily draw resources from other industries.

\section{EXTENSION AND DISCUSSION ${ }^{15}$}

How general are these results? One obvious objection to the assumptions made in the analysis is that the sector-specific capital may not be fixed in the long-run. In this section, we will therefore extend the analysis to allow for endogenous endowments of capital in each sector. ${ }^{16}$ Such an analysis is in a sense biased in favour of positive effects from subsidies: increased rental rates in one activity may increase the supply of capital without reducing

15 This section is largely the result of useful comments by two anonymous referees.

16 The model and the analysis is outlined here, while a more detailed account can be found in Appendix. 
capital stocks in other industries. However, even in this case we cannot be certain that hightech subsidies succeed in expanding aggregate high-tech production.

Let us make the same assumptions as in the long-run analysis in section IV, with the exception that the supply of industry-specific capital now is a functions of its rental rate. For simplicity, we assume that the high-tech activities are symmetrical: factor-intensities, the elasticities of substitution and the elasticities of capital supply with respect to the rental rate are identical in industry 1 and 2 . Since the high-tech sectors are symmetric, we shall only consider uniform production and R\&D subsidies. It is, however, clear that the qualitative insights would be the same with targeted subsidies and asymmetric industries.

Expression (29) shows the effect on aggregate high-tech production of uniform production subsidies:

$$
\hat{X}_{1}+\hat{X}_{2}=\frac{2}{\Delta^{*}}\left[\Phi_{H}+\left(\varphi_{H}+\psi_{H}\right)\left(\delta_{R}^{*}+\delta_{3}^{*}\right)-\lambda_{L H}\left(\rho_{H}+\psi_{H}\right)\left(\pi_{1}^{T *}+\pi_{2}^{T *}\right)\right] \mathrm{d} s
$$

where the subscript $H$ refers to high-tech production; the term $\Phi_{H}$ is defined as $\Phi_{H} \equiv 2 \lambda_{L H} \theta_{K H}^{2} \rho_{H} \psi_{H} ; \psi$ is the elasticity of the capital supply divided by capital's distributive share; the $\varphi^{\prime} s, \lambda^{\prime} s, \rho$ 's and $\theta$ 's have the same interpretation as before; the terms $\delta_{R}^{*}$ and $\delta_{3}^{*}$ are defined as $\delta_{R}^{*} \equiv 2 \lambda_{L R}\left(\rho_{R}+\theta_{L R} \psi_{R}\right)$ and $\delta_{3}^{*} \equiv \lambda_{L X 3}\left(\rho_{3}+\theta_{L X 3} \psi_{3}\right),{ }^{17}$ where the subscripts $R$ and 3 refer to R\&D and the traditional industry, respectively; the term $\pi_{i}^{T *}$ is defined as $\pi_{i}^{T *} \equiv\left(\varphi_{R}+\theta_{L R} \psi_{R}\right)\left(\varepsilon_{i}+\beta_{j} \varepsilon_{j}\right) ; i=1,2 ; j=1,2 ; i \neq j$; and the determinant, $\Delta^{*}$, is positive. ${ }^{18}$

The term $\Phi_{H}$ in (29) illustrates the direct positive effect on high-tech production of the induced increase in capital supply. The rest of the terms are similar to those we had in the case with fixed capital, except that there are now reinforcing effects from changes in the capital stocks. The terms multiplied by $\left(\delta_{R}^{*}+\delta_{3}^{*}\right)$ show the positive reallocation effects

\footnotetext{
17 The $\delta$ 's have a similar but not identical interpretation as in previous sections. They still show how strongly a price increase affects the wage rate, but they are not specified as shares here. Consequently, they do not add up to one when specified for all sectors of the economy.

${ }^{18}$ See Appendix for a definition of the determinant $\Delta^{*}$.
} 
when labour is attracted from other sectors of the economy, i.e. R\&D and the traditional sector. Now, the value of labour's marginal product increases not only as a direct consequence of the subsidisation, but as a consequence of the induced increase in capital, with its positive effect on labour's marginal product, as well.

The last terms in (29) show the negative effect of reduced output in the R\&D sector. This negative effect also contains additional elements when compared with the fixed capital case. As labour moves out of the R\&D sector, the marginal product of capital will fall, and this, in turn, will lead to a reduction in the capital stock (this effect is included in the definitions of the $\pi$ s s). There is, therefore, a tendency for factor productivity in high-tech production to fall more than with fixed capital. In addition, this fall in productivity will now have a stronger negative effect on the output of high-tech goods, since it leads to a negative effect on the capital supply in the high-tech sector.

Thus, we can see that to a large extent the same qualitative trade-offs as already exist in the case with fixed sector-specific capital apply. This conclusion is further strengthened when we consider uniform R\&D subsidies. Expression (30) shows the effect on aggregate high-tech production:

$$
\begin{aligned}
\hat{X}_{1}+\hat{X}_{2}= & \frac{1}{\Delta^{*}}\left[\Phi_{R}\left(1+\varphi_{H}+\psi_{H}\right)\left\{\left(1+\beta_{1}\right) \varepsilon_{1}+\left(1+\beta_{2}\right) \varepsilon_{2}\right\}+\left(\Phi_{H}+\delta_{X}^{*}+\left(\varphi_{H}+\psi_{H}\right) \delta_{3}^{*}\right) \times\right. \\
& \left.\left\{\pi_{1}^{T *}+\pi_{2}^{T *}+\theta_{K R} \psi_{R}\left(\left(1+\beta_{1}\right) \varepsilon_{1}+\left(1+\beta_{2}\right) \varepsilon_{2}\right)\right\}-4 \lambda_{L R}\left(\rho_{R}+\psi_{R}\right)\left(\varphi_{H}+\theta_{L H} \psi_{H}\right)\right] \mathrm{d} q
\end{aligned}
$$

where the subscript $R$ refers to the R\&D sector and the term $\Phi_{R}$ is defined as $\Phi_{R} \equiv 2 \lambda_{L R} \theta_{K R}^{2} \rho_{R} \psi_{R}$. This term illustrates the direct effect on output of R\&D from the induced increase in capital in this sector.

Expression (30) reveals that there are two direct effects on aggregate high-tech production of changes in capital supply. First, the positive effect on R\&D of the increase in R\&D capital will have positive effects on high-tech production, as shown by the first terms in (30) (the terms multiplied with $\Phi_{R}$ ). The resulting increase in factor productivity has a positive effect on output because the given factor inputs become more productive, and, in 
addition, because the employment of both labour and capital increases. The other direct effect of changes in capital supply is shown by the terms multiplied with $\Phi_{H}$. This is the effect of the increase in capital in high-tech production when capital's marginal product increases as a result of increased $R \& D$.

All other terms in (30) represent similar effects to those we had with fixed capital, but, again, these effects are reinforced by the induced changes in the capital stocks. The positive effects from increased $R \& D$; an increase which is now strengthened by the increase in R\&D capital; are now reinforced by increases in capital in high-tech production. Furthermore, when labour is drawn away from the traditional industry, capital's marginal product falls in that sector giving rise to a negative effect on the capital stock. This exerts downward pressure on the wage rate, and more labour can therefore be attracted to $R \& D$ and high-tech production. In a similar manner, the negative effect of the reallocation of labour from high-tech production to R\&D is reinforced by the induced changes in capital stock in both $\mathrm{R} \& \mathrm{D}$ and high-tech production.

This analysis shows that even though there seems to be a stronger presumption for high-tech production to increase with endogenous capital supplies, we still cannot be certain that this will happen. Moreover, there seems to be an even more serious risk that inappropriate policies may cause a substantial fall in high-tech production, since induced changes in capital supplies tend to reinforce the effects of these policies. Hence, the choice of policy-measures is in fact more crucial in the case of endogenous capital endowments.

Another potential objection to the analysis performed in the previous section is that the assumption of constant R\&D prices does not fully capture the interaction between production and R\&D-subsidies. More specifically, one could argue that production subsidies could be expected to lead to increased demand for $R \& D$ and consequenly to increased returns to output of R\&D. In a sense, the policy-choice would be made easier if $R \& D$ in a targeted industry expanded in response to production subsidies, since there would not then be a trade-off between R\&D and final production within the same industry. However, the policy-choice could in another sense be even more difficult: the induced expansion of R\&D in the targeted industry is likely to come about at the expense of a 
contraction of non-targeted $R \& D$ activities. If production subsidies are offered to the industry whose R\&D has the lowest productivity-raising effect, the overall effect on factor productivity in high-tech production may be negative. Furthermore, even in the case of uniform production subsidies, there has to be some degree of substitutability between the high-tech sector and the rest of the economy for aggregate high-tech production to be able to expand.

Finally, a third objection to the way the analysis has been framed is that workers would presumably need to invest in human capital to become scientists and this investment is costly since it requires real resources. If we were to take this into consideration, the results that cast doubt on the possibility of expanding high-tech production by means of industrial targeting would presumably be further strengthened. In educating scientists, other scientists would be needed. Hence, there would be yet another trade-off to consider: the trade-off between resources allocated to education and resources allocated to production and $R \& D$ in the high-tech industries.

\section{CONCLUSIONS}

The main conclusion reached in this paper is that targeted industry subsidies may be ineffective for expanding production in the targeted sectors. Nevertheless, the likelihood of the continuing popularity of high-tech subsidies among policy-makers and the possiblity of certain positive welfare effects from increasing high-tech production leads us to ask how a subsidy scheme might be designed in order to achieve such an increase in high-tech production. In the short-run, the analysis shows that production subsidies are generally preferable to R\&D subsidies. In the long-run, however, there is potentially greater scope for implementing a successful policy of increasing $R \& D$-activities since resources are then also mobile between production and R\&D.

The analysis suggests that targeted subsidies, especially in the case of R\&D-subsidies, require even more detailed knowledge about the structure of the economy, than do uniform subsidies. Therefore, it may be preferable to aim for uniform subsidies. In addition, giving 
both $\mathrm{R} \& \mathrm{D}$ and production subsidies to high-tech industries reduces the risk of choosing policies that have a strong negative effect on high-tech production, a risk that is evident if one only chooses one specific policy. ${ }^{19}$ The worst that can happen with uniform and farreaching subsidies is that resources are not available for expanding high-tech production. In this case, nothing is gained, but on the other hand, however, not very much is lost since the subsidies are simply passed on to factors employed in the high-tech sector.

\section{References}

Brander, J.A. (1995) 'Strategic Trade Policy.' In Handbook of International Economics, Vol. III, ed. G. Grossman and K. Rogoff (Amsterdam: North-Holland).

Brander, J.A. and B.J. Spencer (1985) 'Export subsidies and international market share rivalry,' Journal of International Economics 18, 83-100.

Dixit, A.K., and G. Grossman (1986) 'Targeted export promotion with several oligopolistic industries,' Journal of International Economics 21, 233-49.

Eaton, J. and G. Grossman (1986) 'Optimal Trade and Industrial Policy Under Oligopoly,' Quarterly Journal of Economics 101, 383-406.

Ekholm, K. and J. Torstensson (1995) 'Subsidies to High-Technology Industries: A General Equilibrium Analysis,' mimeo, Department of Economics, Lund University.

Flam, H. and E. Helpman (1987) 'Industrial Policy Under Monopolistic Competition,' Journal of International Economics 22, 79-102.

Jones, R.W. (1971) 'A three factor model in theory, trade, and history.' In Trade, Balance of Payments, and Growth (Amsterdam: North-Holland).

Krugman, P. (1984) 'Import protection as export promotion: International competition in the presence of oligopoly and economies of scale.' In Monopolistic Competition and International Trade, ed. $\mathrm{H}$. Kierzkowski (Oxford: Clarendon Press).

Krugman, P. (1987) 'The narrow moving band, the Dutch disease, and the competitive consequences of Mrs. Thatcher: Notes on trade in the presence of dynamic scale economies', Journal of Development Economies 27, 41-55.

Leahy, D. and J.P. Neary (1996) 'R\&D Spillovers and the Case for Industrial Policy in an Open Economy, mimeo.

Markusen, J.R. (1989) 'Trade in Producer Services and in Other Specialized, Intermediate Inputs,' American Economic Review 79, 85-95.

Markusen, J.R. (1990) 'Derationalizing Tariffs with Specialized Intermediate Inputs and Differentiated Final Goods,' Journal of International Economics 28, 375-384.

Neary, J.P. (1978) 'Short-Run Capital Specificity and the Pure Theory of International Trade', Economic Journal 88, 488-510.

${ }^{19}$ For an analysis of the effects of subsidy schemes that include both production and R\&D subsidies, see Ekholm \& Torstensson (1995). 


\section{APPENDIX}

\section{RESULTS WITH ENDOGENOUS CAPITAL}

\section{The Model}

Zero profit conditions:

$$
\begin{array}{ll}
P_{i}\left(1+s_{i}\right)=\frac{c_{i}\left(w_{L}, w_{K X i}\right)}{\Pi_{i}\left(R_{1}, R_{2}\right)} & \forall i=1,2 \\
P_{3}=c_{i}\left(w_{L}, w_{K X 3}\right) & \\
P_{R j}\left(1+q_{j}\right)=c_{j}\left(w_{L}, w_{K R j}\right) & \forall j=1,2
\end{array}
$$

where $w_{K X i}$ and $w_{K R j}$ are the returns to sector-specific capital in the production and R\&D sector, respectively, and the $c_{i}$ 's have the usual properties of unit cost functions.

Resource constraints:

$$
\begin{array}{lr}
L=\frac{a_{L X 1}}{\Pi_{1}} X_{1}+\frac{a_{L X 2}}{\Pi_{2}} X_{2}+a_{L X 3} X_{3}+a_{L R 1} R_{1}+a_{L R 2} R_{2} \\
K_{X i}\left(w_{K X i}\right)=\frac{a_{K X i}}{\Pi_{i}} X_{i} & \forall i=1,2 \\
K_{X 3}\left(w_{K X 3}\right)=a_{K X 3} X_{3} & \forall j=1,2 \\
K_{R j}\left(w_{K R j}\right)=a_{K R j} R_{j} & \forall j=1,2
\end{array}
$$

where $\quad a_{L X i}=\partial c_{i}\left(w_{L}, w_{K i}\right) / \partial w_{L}, \quad a_{K X i}=\partial c_{i}\left(w_{L}, w_{K X i}\right) / \partial w_{K X i}, \quad \forall \quad i=1, \quad 2, \quad 3 ;$ $a_{L R j}=\partial c_{j}\left(w_{L}, w_{K R j}\right) / \partial w_{L}, a_{K R j}=\partial c_{j}\left(w_{L}, w_{K R j}\right) / \partial w_{K R j}, \forall j=1,2$.

Cost minimisation conditions:

$$
\begin{array}{ll}
\theta_{L X i} \hat{a}_{L X i}+\theta_{K X i} \hat{a}_{K X i}=0 & \forall i=1,2,3 \\
\theta_{L R j} \hat{a}_{L R j}+\theta_{K R j} \hat{a}_{K R j}=0 & \forall j=1,2
\end{array}
$$


Goods prices $\left(P_{1}, P_{2}, P_{3}\right)$, the returns to $\mathrm{R} \& \mathrm{D}\left(P_{R 1}, P_{R 2}\right)$ and the supply of $L$ are assumed to be given, and initial subsidies are set to zero.

\section{$\underline{\text { Results }}$}

We differentiate the resource constraints (A5) - (A7) and use this into the differentiated resource constraint (A4) to eliminate the changes in output levels. We solve the differentiated zero profit conditions (A1) - (A3) for changes in the returns to sector-specific capital and use this in the expression resulting from combining the differentiated resource constraints. By also using the definitions of $\rho_{X i}$ and $\rho_{R j}$, we get the following expression for changes in the wage rate:

$$
\hat{w}_{L}=\frac{1}{\lambda_{L} \xi}\left[\lambda_{L H}\left(\rho_{H}+\psi_{K H}\right)\left(\mathrm{d} s_{1}+\mathrm{d} s_{2}+\hat{\Pi}_{1}+\hat{\Pi}_{2}\right)+\lambda_{L R}\left(\rho_{R}+\psi_{K R}\right)\left(\mathrm{d} q_{1}+\mathrm{d} q_{2}\right)\right]
$$

where we have assumed the following symmetry between the different activities in the hightech sector: $\lambda_{L H} \equiv \lambda_{L X 1}=\lambda_{L X 2} ; \quad \lambda_{L R} \equiv \lambda_{L R 1}=\lambda_{L R 2} ; \quad \rho_{H} \equiv \rho_{X 1}=\rho_{X 2} ; \quad \rho_{R} \equiv \rho_{R 1}=\rho_{R 2}$; $\psi_{H} \equiv \psi_{X 1}=\psi_{X 2} ; \psi_{R} \equiv \psi_{R 1}=\psi_{R 2} ; \theta_{h H} \equiv \theta_{h X 1}=\theta_{h X 2} ; \theta_{h R} \equiv \theta_{h R 1}=\theta_{h R 2}, h=K, L$; the $\psi$ 's are defined as $\psi_{X i} \equiv \hat{K}_{X i} / \theta_{K X i} \hat{w}_{K X i}$ and $\psi_{R j} \equiv \hat{K}_{R j} / \theta_{K R j} \hat{w}_{K R j}$, and $\lambda_{L} \xi \equiv 2 \lambda_{L H}\left(\rho_{H}+\theta_{L H} \psi_{H}\right)+\lambda_{L X 3}\left(\rho_{X 3}+\theta_{L X 3} \psi_{X 3}\right)+2 \lambda_{L R}\left(\rho_{R}+\theta_{L R} \psi_{R}\right)$.

To find changes in output levels for $R \& D$ and high-tech production we use the differentiated resource constraints (A5) and (A7). We use the cost minimisation conditions (A8) - (A9) in the definitions of the $\rho^{\prime}$ 's to solve for $\hat{a}_{K X i}$ and $\hat{a}_{K R_{j}}$, and the differentiated zero profit conditions to solve for $\hat{w}_{K X i}$ and $\hat{w}_{K R j}$. Substituting this into the differentiated resource constraints yields:

$$
\begin{aligned}
& \hat{X}_{i}=\left(\psi_{H}+\varphi_{H}\right) \mathrm{d} s_{i}-\left(\theta_{L H} \psi_{H}+\varphi_{H}\right) \hat{w}_{L}+\left(1+\varphi_{H}+\psi_{H}\right) \hat{\Pi}_{i} \quad \forall i=1,2 \\
& \hat{R}_{j}=\left(\psi_{R}+\varphi_{R}\right) \mathrm{d} q_{j}-\left(\theta_{L R} \psi_{R}+\varphi_{R}\right) \hat{w}_{L}
\end{aligned}
$$

where $\varphi_{H} \equiv \theta_{L H} \rho_{H} ;$ and $\varphi_{R} \equiv \theta_{L R} \rho_{R}$.

We substitute changes in $R_{1}$ and $R_{2}$ from (A12) into expression (10), and then use the resulting expressions in (A10) and (A11):

$$
\begin{aligned}
\hat{w}_{L}= & \frac{1}{\Delta^{*}}\left[\lambda_{L H}\left(\rho_{H}+\psi_{H}\right)\left(\mathrm{d} s_{1}+\mathrm{d} s_{2}+\left(\varphi_{R}+\psi_{R}\right)\left\{\left(1+\beta_{1}\right) \varepsilon_{1} \mathrm{~d} q_{1}+\left(1+\beta_{2}\right) \varepsilon_{2} \mathrm{~d} q_{2}\right\}\right)\right. \\
& \left.+\lambda_{L R}\left(\rho_{R}+\psi_{R}\right)\left(\mathrm{d} q_{1}+\mathrm{d} q_{2}\right)\right]
\end{aligned}
$$




$$
\begin{aligned}
\hat{X}_{i} & =\left(\varphi_{H}+\psi_{H}\right) \mathrm{d} s_{i}+\left(1+\varphi_{H}+\psi_{H}\right)\left(\varphi_{R}+\psi_{R}\right)\left(\varepsilon_{i} \mathrm{~d} q_{i}+\beta_{j} \varepsilon_{j} \mathrm{~d} q_{j}\right) \\
& -\left\{\varphi_{H}+\theta_{L H} \psi_{H}+\left(1+\varphi_{H}+\psi_{H}\right)\left(\varphi_{R}+\theta_{L R} \psi_{R}\right)\left(\varepsilon_{i}+\beta_{j} \varepsilon_{j}\right)\right\} \hat{w}_{L}
\end{aligned}
$$

for $i=1,2 ; j=1,2 ; i \neq j$; where $\Delta^{*} \equiv \lambda_{L} \xi+\lambda_{L H}\left(\rho_{H}+\psi_{H}\right)\left(\pi_{1}^{T *}+\pi_{2}^{T *}\right)$ and $\pi_{i}^{T *} \equiv\left(\varphi_{R}+\theta_{L R} \psi_{R}\right)\left(\varepsilon_{i}+\beta_{j} \varepsilon_{j}\right) ; i=1,2 ; j=1,2 ; i \neq j$.

Substituting (A13) into (A14) and adding the changes in output of the two high-tech goods yield:

$$
\begin{aligned}
\hat{X}_{1}+\hat{X}_{2}= & \frac{1}{\Delta^{*}}\left[\left\{\lambda_{L} \xi\left(\varphi_{H}+\psi_{H}\right)-\lambda_{L H}\left(\rho_{H}+\psi_{H}\right)\left(2\left(\varphi_{H}+\theta_{L H} \psi_{H}\right)+\left(\pi_{1}^{T *}+\pi_{2}^{T *}\right)\right)\right\}\left(\mathrm{d}_{1}+\mathrm{d} s_{2}\right)\right. \\
& -\lambda_{L R}\left(\rho_{R}+\psi_{R}\right)\left\{2\left(\varphi_{H}+\theta_{L H} \psi_{H}\right)+\left(\pi_{1}^{T *}+\pi_{2}^{T *}\right)\left(1+\varphi_{H}+\psi_{H}\right)\right\}\left(\mathrm{d} q_{1}+\mathrm{d} q_{2}\right) \\
& \left.+\left(\varphi_{R}+\psi_{R}\right)\left(\lambda_{L} \xi\left(1+\varphi_{H}+\psi_{H}\right)-2 \lambda_{L H}\left(\varphi_{H}+\theta_{L H} \psi_{H}\right)\left(\rho_{H}+\psi_{H}\right)\right)\left(\left(1+\beta_{1}\right) \varepsilon_{1} \mathrm{~d} q_{1}+\left(1+\beta_{2}\right) \varepsilon_{2} \mathrm{~d} q_{2}\right)\right]
\end{aligned}
$$

after some simplifications. 